\title{
Effect of short courses on perception to use of ultrasound in trauma and ICU settings
}

\section{Thapa A', KC B', Shakya B²}

${ }^{1}$ Amit Thapa, Associate Professor; ${ }^{2}$ Bidur KC, Lecturer; ${ }^{2 B i k r a m ~ S h a k y a, ~ L e c t u r e r, ~ D e p a r t m e n t ~ o f ~ N e u r o l o g i c a l ~ S u r g e r y, ~}$ Kathmandu Medical College Teaching Hospital, Sinamangal, Kathmandu

\begin{abstract}
Backgro und: Since 2012 we have been routinely conducting Kathmandu Medical College Teaching Hospital Ultrasound Trauma Life Support (KUTLS) courses. Unlike detailed examination of an organ with an ultrasound as performed by radiologist, we profess sonoscopic based problem solving approach for the clinician as he uses his stethoscope. The initial skepticism to use of sonoscope in a systematic methodical way has been seen to be fading.

Objectives: We conducted a survey to see the change in knowledge and attitude of the clinicians to use of sonoscopy after a short focused but systematic training program.

Methodology: We studied the questionnaire based feedback forms of the participants in the last 5 course of Kathmandu Medical College Teaching Hospital Ultrasound Trauma Life Support (KUTLS) workshop and analyzed the change in perception and understanding as well as improvement in scores of the post test.

Results: A total of 152 delegates actively participated in five sessions workshops since 2012. The most common reasons to attend the workshop was to develop the skill with sonoscope, $95 \%$ participant did not have any past experience of sonoscopy. Almost $98 \%$ scored more than $75 \%$ in the post-workshop test compared to only $33 \%$ in the pre-workshop test suggesting fast learning curve among the learners. Almost $100 \%$ were convinced with the applicability of the USG and had wished to change their practice.

Conclusion: A structured use of sonoscope would be helpful in clinical practice particularly in solving difficult questions urgently in trauma and Intensive Care Unit. Workshops and seminars help change attitude and practice of the participants even with no prior formal training in ultrasound.
\end{abstract}

Key words: Attitude, ICU, Practice, Sonoscope, Trauma, Ultrasound

\section{INIRODUCTION}

U se of ultrasound as Point-of-care ultrasound (POCUS) by non-radiologist is being accepted in most of the medical programs across the globe. Unlike the radiologist who uses ultrasound to diagnose organ based diseases, a sonologist or a physician uses ultrasound as a tool to answer his clinical query and guide his interventions. For such point of care solutions, ultrasound is just like a stethescope which helps gives images of what is going on inside a patient's body ${ }^{1,2,3}$. In the last 2 decades focused POCUS has been found to be vital in Intensive Care Unit (ICU) and trauma care where

Add ress for correspondence

Dr. Amit Thapa

Associate Professor \& HOD

Department of Neurological Surgery,

Kathmandu Medical College Teaching Hospital, Sinamangal, Kathmandu

Email: dramitthapa@yahoo.com urgent management of airway, breathing and circulation system can be supplemented by sonoscope ${ }^{2,3}$.

Progress in medical education field is allowing early introduction of ultrasound in medical education program around the world ${ }^{5,6}$. Even sub-specialties are integrating POCUS training during their residential training program not limited to anesthesiology, emergency medicine, surgery, gynecology and cardiology $7,8,9$. However, for most of the present day clinicians who had largely been deprived of such training in their medical education, short courses are designed to train and empower them with this technology. The initial skepticism to use of sonoscope in a systematic methodical way has been seen to be fading with more training and exposure ${ }^{7,8,9}$.

Since 2012, we at Kathmandu Medical College Teaching Hospital (KMCTH) have been organizing routine KMCTH ultrasound trauma life support (KUTLS) courses for clinicians. We had made materials derived from various 
sources and structured them into Advanced Trauma Life Support (ATLS) protocol and ICU based practices which were used together with hands on training on animal models for the courses $2,3,10,11,12,13$.

We conducted this study to analyze the impact of such short courses on perception and attitude of participants to use of ultrasound as point of care gadget in trauma and ICU settings.

\section{METHODOLOGY}

At KMCTH, we designed a comprehensive yet compact one-day course for exposing clinicians to use of ultrasound in trauma and ICU setting. These one day courses were designed in 3 parts, the first dealing with basics of Ultrasound, second with ATLS and the third dealing with ICU (Table 1). A structured course comprising of lectures on how to use the sonoscope in different clinical conditions along the principle of ATLS in trauma conditions as well as how to use in ICU for shock and respiratory conditions and intervention procedures was conducted. These clinical conditions were answered with binary outcomes, for example either there is blood in Morrison pouch or not. Besides hands-on experience on healthy volunteers as well as chicken animal model gave participants a real life exposure (Figures $1 \& 2$ ). In addition, videos of pathologies were narrated to help identify the conditions. We included all participants in the last 5 courses conducted between November 2012 and February 2016. All participants were supposed to write a pre and post-workshop tests. These tests were knowledge based multiple choice questions to analyze how much the participants know and have learned from the workshop. Besides participants were given a questionnaire based feedback form to understand their background, expectations and perceptions about the course (Table 2). The feedback received and change in pre and post-workshop test scores were evaluated for change in perception, interest and knowledge of participants to use ultrasound in their practice.

These data were tabulated in Excel Sheet and analyzed using Stastistical Package for Social Sciences Software Version 16.

\section{RESUITS}

A total of 171 delegates actively participated in the last five sessions of KUTLS workshops, of which 152(88.9\%) responded to questionnaires and feedback requests. All the participants attended a structured one-day course comprising of lectures and hands-on experience on healthy volunteers as well as chicken animal model.
Delegates were from the Specialties of Accident and Emergency (A\&E), General Surgery, Anesthesiology, Internal Medicine, Radiology and Orthopedic from different parts of Nepal. Age of the participants ranged from 28 to 35 years. About $28 \%$ of participants were post graduate trainees followed by $26.6 \%$ who were consultants and $23 \%$ were MBBS doctors and rest $21.1 \%$ were medical students (Table 3).

Altogether $144 \quad(94.7 \%)$ responders reported not having any prior experience of ultrasonography. 100\% participants attended the program with the common objective of developing skills with sonoscopy and acquiring new information. Since in Nepal there is no mandatory requirement for annual CME points, none of the participants quoted it as a reason to attend the Continuing Medical Education (CME). A total of $99.3 \%$ participants joined the course to learn sonoscopy with $98.7 \%$ influenced by the list of topics.

Nearly three fifth participants were interested towards the course by the word of mouth as compared to $36.2 \%$ who were influenced by posts on social sites like viber and facebook.

Regarding the educational activity, none of the participants reported educational content, relevance to practice, question or discussion or quality of presenters or topics as average or below average or poor. $99.3 \%$ delegates found the course relevant to their practice. The majority $(96.7 \%)$ appreciated the knowledge of the presenter and found them organized and effective in their presentation, with $95.4 \%$ attendees admitting to have an opportunity to clarify their doubts.

Almost $82.2 \%$ of the participants found the format appropriate and recommended no further changes, however $16.5 \%$ wished a longer session with sub topics to be discussed further and $13.2 \%$ wanted more interaction. Likewise, $6.6 \%$ wanted more case based discussion and a similar number wished to have additional question and answer sessions.

Overall, 99.3\% participants believed that the course met their needs and filled their professional gaps. All of them rated these course to have a high impact (scored 4 in 4 band rating scale) on their knowledge and patient outcomes with $92.1 \%$ and $91.4 \%$ assessing a high impact on their competence and performance respectively. $100 \%$ of them believed that such course would change their practice by helping them to create or revise protocols or procedures as well as change management paradigm. 
However, $32.9 \%$ perceived barriers to the introduction of this technology in their workplace, the commonest of which was unavailability of portable dedicated ultrasound machine.

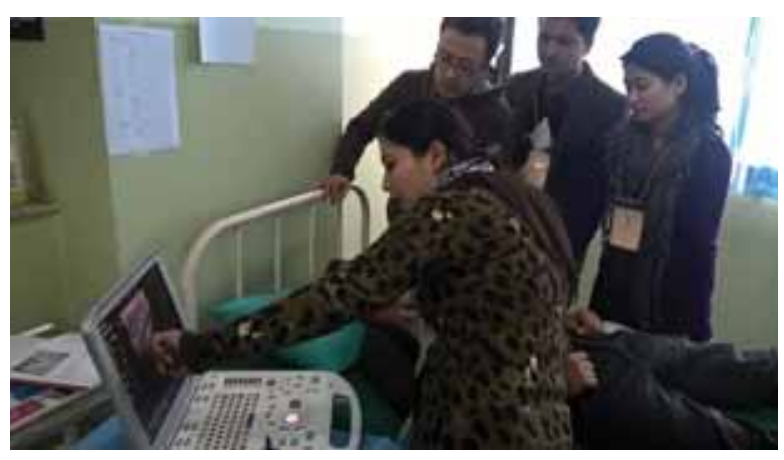

Figure 1: Participants performing airway ultrasound under supervision on standardized patient
After the course, 98\% participants scored more than $75 \%$ in post-workshop tests as compared to 50 (32.9\%) participants in their pre-workshop tests. This suggested a fast learning curve and developing interest in the participants.

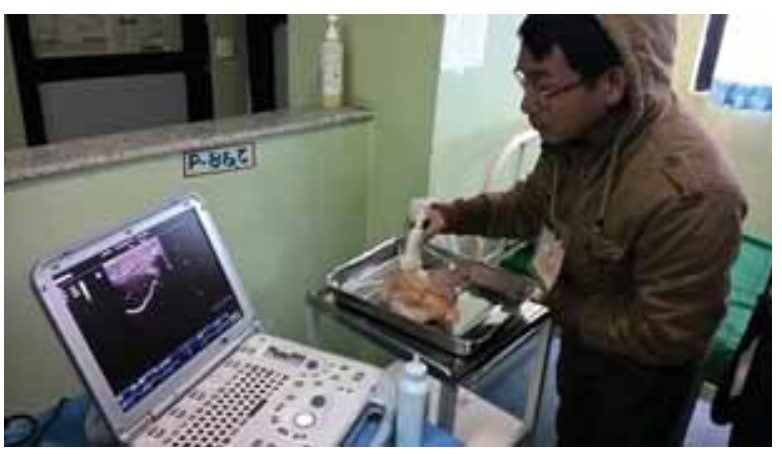

Figure 2: Participant performing ultrasound guided intervention in chicken model

Table 1: Outline of KUTLS workshop

\begin{tabular}{|c|c|c|}
\hline \multicolumn{3}{|c|}{ Outline of KMCTH Ultrasound Trauma Life Support (KUTLS) workshop } \\
\hline Items & Topics & Content \\
\hline \multirow[t]{2}{*}{ Basics of Ultrasound (Sonoscope) } & Introduction to course & \\
\hline & Knobology & Technical knowledge of ultrasonic waves and ultrasound machine \\
\hline \multirow[t]{6}{*}{ ATLS with Sonoscope } & ABCDE BY ULTRASOUND & \\
\hline & Airway & $\begin{array}{l}\text { Airway ultrasound anatomy } \\
\text { Tracheal injuries } \\
\text { Threatened airway } \\
\text { Airway confirmation } \\
\text { Procedures- Needle cricothyroidotomy, Tracheostomy }\end{array}$ \\
\hline & Breathing & $\begin{array}{l}\text { Assessment: } \\
\text { Pneumothorax, Pleural effusion, Lung contusion, Pneumonia, } \\
\text { Diaphragm impairment } \\
\text { Procedures: } \\
\text { Needle aspiration, thoraco-centesis, chest tube insertion, } \\
\text { thoracotomy } \\
\text { US-enhanced Trauma Management: } \\
\text { Respiratory Protocols \& Interactive Cases [BLUE] }\end{array}$ \\
\hline & Circulation & $\begin{array}{l}\text { RUSH PROTOCOL } \\
\text { The Pump- Cardiac Ultrasound in Trauma } \\
\text { The Tank- E-FAST } \\
\text { The pipes (Aorta, IVC, DVT scan }\end{array}$ \\
\hline & Disability & Optic nerve sheath/disc, pupil assessment \\
\hline & Secondary survey & $\begin{array}{l}\text { Concepts on Head-to-Toes } \\
\text { Secondary Management \& Monitoring: } \\
\text { - Head, Thorax, Abdomen, Limbs } \\
\text { - Assessment, treatment, monitoring, and follow-up }\end{array}$ \\
\hline \multirow[t]{2}{*}{ Supplementary ICU practices } & $\begin{array}{l}\text { USG guided central } \\
\text { venous cannulation }\end{array}$ & $\begin{array}{l}\text { Ultrasound guided intervention } \\
\text { Cannulation of IJV \& Subclavian Vein }\end{array}$ \\
\hline & Ultrasound Guided CPR & \\
\hline
\end{tabular}




\section{Table 2: Workshop evaluation form}

\begin{tabular}{|c|c|c|c|c|c|}
\hline \multicolumn{6}{|c|}{ KUTLS workshop evaluation form } \\
\hline 1. Presently working as & 1- Medical Students & 2- MBBS doctors & $\begin{array}{l}\text { 3- Post graduates } \\
\text { trainees }\end{array}$ & $\begin{array}{l}\text { 4- Registrars/ } \\
\text { Consultants }\end{array}$ & \\
\hline $\begin{array}{l}\text { 2. Prior experience with } \\
\text { ultrasound }\end{array}$ & $1-$ Yes & 2- No & & & \\
\hline $\begin{array}{l}\text { 3. What influenced you to } \\
\text { attend this meeting (can tick } \\
\text { more than one) }\end{array}$ & $\begin{array}{l}\text { 1- course (to learn } \\
\text { sonoscopy) }\end{array}$ & 2- list of faculty & 3- list of topics & 4- fee & 5-host site \\
\hline $\begin{array}{l}\text { 4. Indicate the reason you } \\
\text { came to the meeting (can tick } \\
\text { more than one) }\end{array}$ & $\begin{array}{l}\text { 1- to develop clinical } \\
\text { skills }\end{array}$ & $\begin{array}{l}\text { 2- to develop } \\
\text { interpretive and } \\
\text { diagnostic skills }\end{array}$ & $\begin{array}{l}\text { 3- to acquire new } \\
\text { information on the } \\
\text { subject }\end{array}$ & $\begin{array}{l}\text { 4- to review the } \\
\text { subject }\end{array}$ & $\begin{array}{l}\text { 5- to meet } \mathrm{CME} \\
\text { requirements }\end{array}$ \\
\hline $\begin{array}{l}\text { 5. How did you obtain } \\
\text { information on this program }\end{array}$ & 1- online/ Social sites & 2- email & 3- mailed brochure & $\begin{array}{l}\text { 4- word of } \\
\text { mouth }\end{array}$ & \\
\hline \multicolumn{6}{|l|}{$\begin{array}{l}\text { 6. Please rate the overall } \\
\text { aspects of this educational } \\
\text { activity on the basis of }\end{array}$} \\
\hline Educational content & 1-poor & 2-Below Average & 3- Average & $\begin{array}{l}\text { 4- above } \\
\text { average }\end{array}$ & 5- outstanding \\
\hline Relevance to practice & 1-poor & 2- Below Average & 3- Average & $\begin{array}{l}\text { 4- above } \\
\text { average }\end{array}$ & 5- outstanding \\
\hline Questions and discussions & 1-poor & 2- Below Average & 3-Average & $\begin{array}{l}\text { 4- above } \\
\text { average }\end{array}$ & 5- outstanding \\
\hline Quality of presenters & 1-poor & 2-Below Average & 3-Average & $\begin{array}{l}\text { 4- above } \\
\text { average }\end{array}$ & 5- outstanding \\
\hline Selection of topics & 1-poor & 2-Below Average & 3-Average & $\begin{array}{l}\text { 4- above } \\
\text { average }\end{array}$ & 5- outstanding \\
\hline Overall quality of activity & 1-poor & 2-Below Average & 3-Average & $\begin{array}{l}\text { 4- above } \\
\text { average }\end{array}$ & 5- outstanding \\
\hline $\begin{array}{l}\text { 7. Presenter: to what } \\
\text { extent was the presenter } \\
\text { knowledgeable, organized }\end{array}$ & 1-poor & 2- Below Average & 3-Average & $\begin{array}{l}\text { 4- above } \\
\text { average }\end{array}$ & 5- outstanding \\
\hline
\end{tabular}

and effective in his/ her

presentation?

8. Did you have the

opportunity to discuss

practice relevant issues with

1- Yes

2- No

the speakers

9. How might the format of

this activity be improved in

order to be most appropriate

for the content presented?

1-format was

appropriate, no

changes needed

$\begin{array}{cc}\text { 2-include more } & \text { 3-increase } \\ \text { case-based } & \text { interactivity with } \\ \text { presentations } & \text { attendees }\end{array}$

presentations
4- Add

breakouts for

sub topics
5- Schedule more time for

$\mathrm{Q}$ and $\mathrm{A}$
6- Others, describe

(can tick more than one)

10. Has this activity met

your identified needs and

1-Yes

2- No

professional practice gaps

11. Please rate the overall

impact of this activity

objective on:

\begin{tabular}{|c|c|c|c|}
\hline Knowledge & 1- Not applicable & 2- No impact & 3-Moderate impact 4- High impact \\
\hline Competence & 1- Not applicable & 2- No impact & 3-Moderate impact 4- High impact \\
\hline Performance & 1- Not applicable & 2- No impact & 3-Moderate impact 4- High impact \\
\hline Patient outcomes & 1- Not applicable & 2- No impact & 3-Moderate impact 4- High impact \\
\hline
\end{tabular}


Thapa A et al.

Table 2 cont ...

\begin{tabular}{|c|c|c|c|c|c|}
\hline $\begin{array}{l}\text { 12. How will you change } \\
\text { your practice as a result of } \\
\text { attending this activity }\end{array}$ & $\begin{array}{l}\text { 1- create/ revise } \\
\text { protocols, policies, } \\
\text { procedures }\end{array}$ & $\begin{array}{l}\text { 2- change the } \\
\text { management \& } \\
\text { treatment of my } \\
\text { patients }\end{array}$ & $\begin{array}{l}\text { 3-this activity } \\
\text { validates my } \\
\text { current practice }\end{array}$ & $\begin{array}{l}\text { 4-I will not } \\
\text { make any } \\
\text { changes to my } \\
\text { practice }\end{array}$ & $\begin{array}{l}\text { 5- Others } \\
\text { please specify }\end{array}$ \\
\hline $\begin{array}{l}\text { 13. Any perceived barriers in } \\
\text { making changes identified }\end{array}$ & 1-Yes & 2- No & If yes specify & & \\
\hline $\begin{array}{l}\text { 14. Based on your needs, } \\
\text { provide suggestions for future } \\
\text { program topics/ formats }\end{array}$ & & & & & \\
\hline
\end{tabular}

\section{Table 3: Analysis of Feedbacks received from the participants $(\mathbf{n}=\mathbf{1 5 2}$ )}

\begin{tabular}{|c|c|c|c|c|c|}
\hline Presently working as & $\begin{array}{l}\text { 1- Medical } \\
\text { Students }\end{array}$ & 2- MBBS doctors & $\begin{array}{l}\text { 3- Post graduates } \\
\text { trainees }\end{array}$ & $\begin{array}{l}\text { 4- Registrars/ } \\
\text { Consultants }\end{array}$ & \\
\hline & $32(21.1 \%)$ & $35(23 \%)$ & $43(28.3 \%)$ & $42(26.6 \%)$ & \\
\hline \multirow{2}{*}{$\begin{array}{l}\text { Prior experience with } \\
\text { ultrasound }\end{array}$} & 1-Yes & 2- No & & & \\
\hline & $8(5.3 \%)$ & $144(94.7 \%)$ & & & \\
\hline \multirow{2}{*}{$\begin{array}{l}\text { 11. What influenced you to } \\
\text { attend this meeting (can tick } \\
\text { more than one) }\end{array}$} & $\begin{array}{l}\text { 1- course (to learn } \\
\text { sonoscopy) }\end{array}$ & 2- list of faculty & 3- list of topics & 4-fee & 5-host site \\
\hline & $151(99.3 \%)$ & $95(62.5 \%)$ & $150(98.7 \%)$ & $85(55.9 \%)$ & $136(89.5 \%)$ \\
\hline \multirow[t]{2}{*}{$\begin{array}{l}\text { 2. Indicate the reason you } \\
\text { came to the meeting (can tick } \\
\text { more than one) }\end{array}$} & $\begin{array}{l}\text { 1- to develop } \\
\text { clinical skills }\end{array}$ & $\begin{array}{l}\text { 2- to develop } \\
\text { interpretive and } \\
\text { diagnostic skills }\end{array}$ & $\begin{array}{l}\text { 3- to acquire new } \\
\text { information on the } \\
\text { subject }\end{array}$ & $\begin{array}{l}\text { 4- to review the } \\
\text { subject }\end{array}$ & $\begin{array}{l}\text { 5- to meet } \mathrm{CME} \\
\text { requirements }\end{array}$ \\
\hline & $152(100 \%)$ & $145(95.4 \%)$ & $152(100 \%)$ & $3(2 \%)$ & 0 \\
\hline \multirow[t]{2}{*}{$\begin{array}{l}\text { 10. How did you obtain } \\
\text { information on this program }\end{array}$} & $\begin{array}{l}\text { 1- online/ Social } \\
\text { sites }\end{array}$ & 2- email & 3- mailed brochure & 4- word of mouth & \\
\hline & $55(36.2 \%)$ & $2(1.3 \%)$ & $5(3.3 \%)$ & $90(59.2 \%)$ & \\
\hline $\begin{array}{l}\text { 4. Please rate the overall } \\
\text { aspects of this educational } \\
\text { activity on the basis of }\end{array}$ & 1-poor & 2- Below Average & 3- Average & 4- above average & 5- outstanding \\
\hline Educational content & 0 & 0 & 0 & $12(7.9 \%)$ & $140(92.1 \%))$ \\
\hline Relevance to practice & 0 & 0 & 0 & $1(0.7 \%)$ & 151 (99.3\%) \\
\hline Questions and discussions & 0 & 0 & 0 & $7(0.6 \%)$ & 145 (95.4\%) \\
\hline Quality of presenters & 0 & 0 & 0 & $50(22.9 \%)$ & $102(67.1 \%)$ \\
\hline Selection of topics & 0 & 0 & 0 & $7(4.6 \%)$ & 145 (95.4\%) \\
\hline Overall quality of activity & 0 & 0 & 0 & $6(3.9 \%)$ & $146(96.1 \%)$ \\
\hline \multirow[t]{2}{*}{$\begin{array}{l}\text { 1. Presenter: to what } \\
\text { extent was the presenter } \\
\text { knowledgeable, organized } \\
\text { and effective in his/ her } \\
\text { presentation? }\end{array}$} & 1-poor & 2- Below Average & 3- Average & 4- above average & 5- outstanding \\
\hline & 0 & 0 & $5(3.3 \%)$ & $46(30.3 \%)$ & $101(66.4 \%)$ \\
\hline \multirow[t]{2}{*}{$\begin{array}{l}\text { 5. Did you have the } \\
\text { opportunity to discuss } \\
\text { practice relevant issues with } \\
\text { the speakers }\end{array}$} & 1-Yes & 2- No & & & \\
\hline & 145 (95.4\%) & $7(4.6 \%)$ & & & \\
\hline
\end{tabular}


Table 3 cont ...

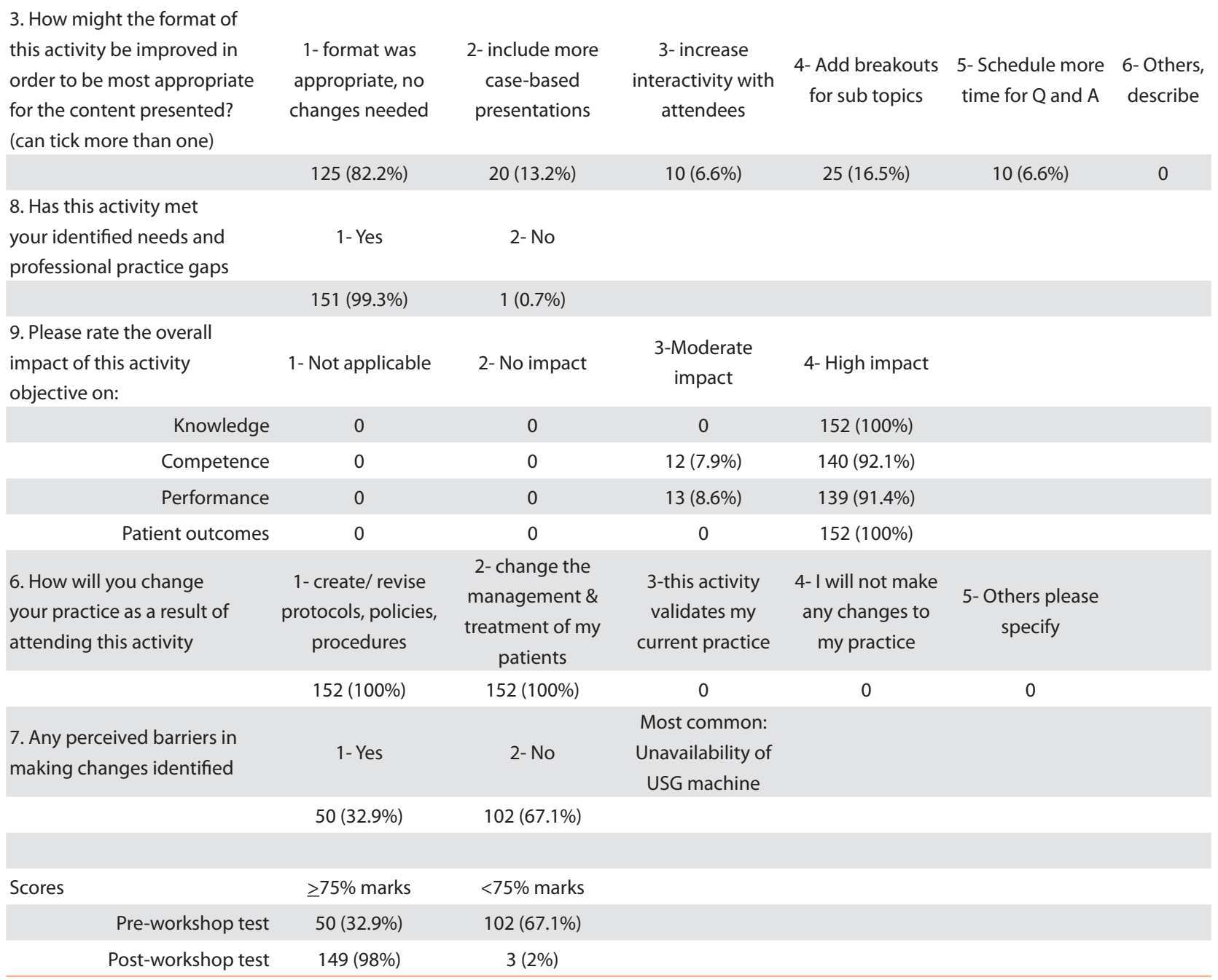

\section{DISCUSSON}

After its invention, it took almost a century for the ultrasonography to be used for medical reasons with Austrian neurologist Karl Theo Dussik outlining the ventricle in $1941^{4}$. However despite its tremendous potential, ultrasound remains a tool largely used by radiologist. A major reason for this skepticism in general medical population has been due to lack of exposure and training during basic medical training programs.

Sonoscopy rather than ultrasonography is being taught to non radiologist to enable them to answer their clinical queries in emergency as well as resuscitative procedures rather than organ based detailed evaluation as performed by radiologist. Answer in either as 'yes' or 'no' shall help them to make quick clinical judgment. Such Point of care ultrasound or POCUS is being promoted in the last decade around the hospitals all over the world as focused structured approach of sonography ${ }^{1,2,3}$.

The major skepticism is based on a fear that such learning would not be enough as it needs years to learn and practice ultrasonography. However, at some time in one's career, he has to make a start! Once the base is made, more learning and refinement in practice can be built upon.

We have seen cardiologist and gynecologist use ultrasound as echocardiograph and fetoscope respectively with dexterity even though they start learning late during their sub-specialty training.

Hence a course which is designed in a structured format and provides didactic lecture with video demonstration 
for understanding and hands-on experience on models can very well fill the gap.

This study supports this fact that as the participants scored well in their post-workshop test in spite of them not having pre-workshop ultrasound experience suggesting a fast learning curve. Kotagal et al in their cohort study of 16 residents who were exposed to POCUS training course showed improved self efficacy and confidence levels across a broad range of skills. ${ }^{8}$ Similar results were reported by Ramsingh et al in their experience with the integrated whole body POC ultrasound curriculum for anesthesiology residents ${ }^{9}$.

We started this course for the first time in Nepal with the help of colleagues from All India Institute of Medical Sciences (AlIMS), New Delhi in 2012. Since then we have been able to conduct these courses yearly with special emphasis on participants' needs and learning experience. This has been reflected by the participant's high rating to our course content, relevance to practice and quality of presentations. Besides $59 \%$ have been interested towards our short course by the word of mouth or referrals.

We have seen a positive impact on the attitude and knowledge of the participants with all of them wanting to use sonography in their practice. This major change in the attitude has been possible due to interest and fast learning curve of the participants.

Medical Educators have identified a possibility of harm by employing ultrasound while learning physical examination if used outside the intended scope ${ }^{5}$. Hence, such an educative program should be thoughtfully designed and targeted. Limitations and what not to be done should be thoroughly discussed. It is very important to impress upon the participants as well as

\section{REFERENGES}

1. Filly RA. Ultrasound: the stethoscope of the future, alas. Radiol. 1988;167(2):400.

2. Abu-Zidan FM. Point-of-care ultrasound in critically ill patients: Where do we stand? J Emerg, Trauma, Shock. 2012;5:70-71.

3. Greenbaum LD. It is time for the sonoscope. J Ultrasound in Med. 2003;22:321-232.

4. Dussik KT. On the possibility of using ultrasound waves as a diagnostic aid. Neurol Psychiat. 1942;174:153-68.

5. Ma I, Wishart I, Kaminska M, Kevin M. Weeks S, Lautner D. Baxter H, Wright B. Medical educators' the tutors that sonography is a life long learning process like any other medical specialties with its fallacies and both over confidence as well under confidence needs auditing of ones' results and training to improvise.

In resource poor settings like ours, the lack of diagnostic equipment and trained personnel remains a major barrier to health care delivery. In such scenarios, point of care ultrasound (POCUS) is a sustainable high impact technology which can be easily learned, can help confirm diagnosis and change clinical decision making as well help guide interventions. These skills can be readily transferable to midlevel providers like midwives, emergency evacuation teams and nurses ${ }^{8}$.

There is no doubt that early introduction of ultrasound to medical undergraduates and post graduates would certainly help them make efficient clinicians. However exposure during any time of their career can also help generate interest and by proper training and frequent use they can use sonoscope in their everyday dealing with the patients.

\section{CONAUSON}

After having conducted KUTLS workshops and seen the difference it makes in perception, knowledge and attitude of the clinicians, we recommend a structured use of sonoscope which would be helpful in clinical practice particularly in solving difficult clinical questions in trauma and ICU. Workshops and seminars help change attitude and practice of the participants even with no prior formal training in sonoscopy.

\section{ACKNOWEDGEMENT}

We express our gratitude to the team of faculties at $\mathrm{KMCTH}$ for showing the commitment and conducting routinelyultrasound workshop to facilitate dissemination of knowledge and skills.

perspectives of teaching physical examinations using ultrasonography at the undergraduate level. CMEJ . 2013;4(1):e59-e68.

6. Hoppmann R, Rao VV, Poston MB, Howe DB, Hunt PS, Fowler SD et.al. An integrated ultrasound curriculum (iUSC) for medical students: 4-year experience. Crit Ultrasound J. 2011;3:1-12.

7. Jones $A E$, Tayal VS, Kline JA. Focused training of emergency medicine residents in goal-directed echocardiography: a prospective study. Acad Emerg Med. 2003 Oct;10(10):1054-8.

8. Kotagal M, Quiroga E, Ruffatto BJ, Adedipe AA, Backlund BH, Nathan R et.al. Impact of point-of- 
care ultrasound training on surgical residents' confidence. J Surg Educ. 2015 J ul-Aug;72(4):e82-7.

9. Ramsingh D, Rinehart J, Kain Z, Strom S, Canales C, Alexander B et.al. Impact assessment of perioperative point-of-care ultrasound training on anesthesiology residents. Anesthesiology. 2015 Sep;123(3):670-82.

10. Gillman LM, Ball CG, Panebianco N, Al-Kadi A, Kirkpatrick AW. Clinician performed resuscitative ultrasonography for the initial evaluation and resuscitation of trauma. Scandinavian J Trauma, Resuscitation and Emergency Med. 2009;17:17-34.
11. Gillman LM, Kirkpatrick AW. Portable bedside ultrasound: the visual stethoscope of the 21st century. Scandinavian Journal of Trauma, Resuscitation and Emergency Medicine 2012;20:18.

12. Seif $D$, Perera $P$, Mailhot $T$, David Riley $D$, Mandavia D. Bedside Ultrasound in Resuscitation and the Rapid Ultrasound in Shock Protocol. Critical Care Research and Practice. 2012;503254:1-14.

13. Bouhemad B, Zhang M, Qin Lu Q, Rouby JJ. Clinical review: Bedside lung ultrasound in critical care practice. Critical Care. 2007;11:205. 